\title{
Allometric Analysis Detects Brain Size-Independent Effects of Sex and Sex Chromosome Complement on Human Cerebellar Organization
}

\author{
Catherine Mankiw, ${ }^{1}$ Min Tae M. Park, ${ }^{2,3}$ P.K. Reardon, ${ }^{1}$ Ari M. Fish, ${ }^{1}$ Liv S. Clasen, ${ }^{1}$ Deanna Greenstein, ${ }^{1}$ Jay N. Giedd, ${ }^{4}$ \\ Jonathan D. Blumenthal, ${ }^{1}$ Jason P. Lerch, ${ }^{5,6}$ M. Mallar Chakravarty, ${ }^{2}$ and ${ }^{\circledR}$ Armin Raznahan ${ }^{1}$ \\ 'Developmental Neurogenomics Unit, Child Psychiatry Branch, National Institute of Mental Health, Bethesda, Maryland 20892, ${ }^{2}$ Cerebral Imaging Center, \\ Douglas Mental Health University Institute, Montreal, Quebec H4H 1R3, Canada, ${ }^{3}$ Schulich School of Medicine and Dentistry, Western University, London, \\ Ontario N6A 5C1, Canada, ${ }^{4}$ Department of Psychiatry, University of California San Diego, La Jolla, California 92093, ${ }^{5}$ Department of Medical Biophysics, \\ University of Toronto, Toronto, Ontario M5G 1L7, Canada, and ${ }^{6}$ Department of Psychiatry and Biomedical Engineering, McGill University Montreal, \\ Quebec H3A 2B4, Canada
}

The cerebellum is a large hindbrain structure that is increasingly recognized for its contribution to diverse domains of cognitive and affective processing in human health and disease. Although several of these domains are sex biased, our fundamental understanding of cerebellar sex differences - including their spatial distribution, potential biological determinants, and independence from brain volume variation-lags far behind that for the cerebrum. Here, we harness automated neuroimaging methods for cerebellar morphometrics in 417 individuals to (1) localize normative male-female differences in raw cerebellar volume, (2) compare these to sex chromosome effects estimated across five rare sex (X/Y) chromosome aneuploidy (SCA) syndromes, and (3) clarify brain size-independent effects of sex and SCA on cerebellar anatomy using a generalizable allometric approach that considers scaling relationships between regional cerebellar volume and brain volume in health. The integration of these approaches shows that (1) sex and SCA effects on raw cerebellar volume are large and distributed, but regionally heterogeneous, (2) human cerebellar volume scales with brain volume in a highly nonlinear and regionally heterogeneous fashion that departs from documented patterns of cerebellar scaling in phylogeny, and (3) cerebellar organization is modified in a brain size-independent manner by sex (relative expansion of total cerebellum, flocculus, and Crus II-lobule VIIIB volumes in males) and SCA (contraction of total cerebellar, lobule IV, and Crus I volumes with additional X- or Y-chromosomes; $\mathrm{X}$-specific contraction of Crus II-lobule VIIIB). Our methods and results clarify the shifts in human cerebellar organization that accompany interwoven variations in sex, sex chromosome complement, and brain size.

Key words: cerebellum; development; genetics; neuroimaging

\section{Significance Statement}

Cerebellar systems are implicated in diverse domains of sex-biased behavior and pathology, but we lack a basic understanding of how sex differences in the human cerebellum are distributed and determined. We leverage a rare neuroimaging dataset to deconvolve the interwoven effects of sex, sex chromosome complement, and brain size on human cerebellar organization. We reveal topographically variegated scaling relationships between regional cerebellar volume and brain size in humans, which (1) are distinct from those observed in phylogeny, (2) invalidate a traditional neuroimaging method for brain volume correction, and (3) allow more valid and accurate resolution of which cerebellar subcomponents are sensitive to sex and sex chromosome complement. These findings advance understanding of cerebellar organization in health and sex chromosome aneuploidy.

\section{Introduction}

A detailed understanding of sex differences in brain development is critical to the study of well documented male-female differ-

Received June 29, 2016; revised Jan. 30, 2017; accepted Feb. 1, 2017.

Author contributions: C.M., D.G., J.N.G., and A.R. designed research; C.M., M.T.M.P., P.K.R., A.M.F., L.S.C., D.G., J.N.G., J.D.B., J.P.L., and A.R. performed research; C.M. and M.T.M.P. contributed unpublished reagents/analytic tools; C.M. and A.R. analyzed data; C.M. and A.R. wrote the paper. ences in cognition, behavior, and risk for mental illness (Rutter et al., 2003; Roalf et al., 2014). While there is convergent evidence of regionally specific neuroanatomical sex differences in the human cerebrum from multiple in vivo structural neuroimaging studies (Gur et al., 2002; Sowell et al., 2003; Raznahan et al., 2010; Rear-
This research was supported by the Intramural Research Program of the National Institute of Mental Health. We thank the participants and families who took part in this study.

The authors declare no competing financial interests. 
Table 1. Participant characteristics

\begin{tabular}{|c|c|c|c|c|c|c|c|c|}
\hline \multirow[b]{2}{*}{ Characteristic } & \multicolumn{7}{|l|}{ Core sample } & \multirow[b]{2}{*}{ Allometric sample } \\
\hline & $X X$ & $X Y$ & $X X X$ & $X X Y$ & $X Y Y$ & XXYY & XXXXY & \\
\hline $\begin{array}{l}\text { Sample size } \\
\text { Age (years) }\end{array}$ & 80 & 88 & 28 & 56 & 25 & 19 & 5 & 116 (50 F/66 M) \\
\hline Range & $5.4-25.1$ & $5.2-25.5$ & $5.0-24.8$ & $5.2-26.0$ & $5.7-23.1$ & $5.1-23.0$ & $7.7-17.2$ & $12.0-14.0$ \\
\hline FSIQ & & & & & & & & \\
\hline $\begin{array}{l}\text { Mean }(S D)^{*} \\
\text { SES }\end{array}$ & $114(12.2)$ & $117(13.3)$ & $94(14.2)$ & $98(17.1)$ & $91(14.6)$ & $87(12.9)$ & $56(7.3)$ & $117(12.3)$ \\
\hline
\end{tabular}

F, Female; M, male; FSIQ, Full Scale IQ; SES, socioeconomic status.

${ }^{*} p<0.01$ for omnibus test of significant variation across groups in the core sample.

don et al., 2016), sex differences within the human cerebellum remain poorly resolved (Tiemeier et al., 2010). Specifically, it is well established that males, on average, have greater total cerebellar volume (TCbV) than females (by 8-13\%; Giedd et al., 1996; Leonard et al., 2008; Tiemeier et al., 2010), but the regional distribution of sex differences in cerebellar volume and their independence from accompanying sex differences in total brain volume (Giedd et al., 2012) remain unclear. This gap in knowledge is problematic given the region-specific nature of cerebellar involvement in sex-biased domains of cognition and psychopathology (e.g., language development, autism spectrum disorder, and attention deficit hyperactivity disorder; Stoodley and Schmahmann, 2009; Strick et al., 2009; Stoodley, 2016).

Characterizing regional sex differences in human cerebellar anatomy is significantly challenged by the ongoing lack of data regarding normative scaling relationships between regional cerebellar volume and overall brain size in humans (Charvet et al., 2013). Because scaling relationships between regional and global brain volumes can be profoundly nonlinear in humans, scaling (or allometric) norms provide a critical framework for valid comparison of regional anatomy between males and females or any other groups that differ in brain size (Raznahan et al., 2016; Reardon et al., 2016). Securing a detailed map of regional cerebellar allometry in humans is also important for our basic understanding of cerebellar morphogenesis, and is well motivated by both phylogenetic (Finlay and Darlington, 1995; Clark et al., 2001; Balsters et al., 2010; Charvet et al., 2013) and developmental (Sudarov and Joyner, 2007; Legué et al., 2015) evidence that the factors that determine global and regional cerebellar size are partially dissociable from those determining overall brain size.

A second challenge in the study of cerebellar sex differences in humans is the paucity of studies that directly test whether sexbiased hormonal and genetic effects (Arnold, 2014) can influence cerebellar development. Sex chromosome effects represent a priority for further study in this regard given that (1) sex chromosome complement can modify cerebellar anatomy in mice independently of sex differences in circulating sex steroids (Corre et al., 2016) and (2) sex chromosome aneuploidies (SCAs) such as XXY and XYY syndrome are associated with impairments in several cerebellar-dependent cognitive domains, including motor control, language, and executive functioning (Hong and Reiss, 2014). To date, however, it remains unknown whether and how X- and Y-chromosome aneuploidy affects cerebellar anatomy in humans. Furthermore, it is unclear whether such

Correspondence should be addressed to Armin Raznahan, National Institutes of Health, 10 Center Drive, Building 10, Room 4D18, MSC 1367, Bethesda, MD 20892. E-mail: raznahana@mail.nih.gov.

DOI:10.1523/JNEUROSCI.2158-16.2017

Copyright (C) 2017 the authors $\quad 0270-6474 / 17 / 375222-11 \$ 15.00 / 0$ effects are congruent with normative sex differences in cerebellar anatomy (e.g., X-chromosome-induced volume reductions where cerebellar volume is smaller in females than males) independent of known sex and SCA effects on overall brain size (Raznahan et al., 2016).

Here, we use an allometric framework to study sex and SCA effects on human cerebellar anatomy. Our "core sample" includes multiple individually rare SCA syndromes, and comprises a total of 301 participants who were 5-25 years of age with one of seven different sex chromosome karyotypes (i.e., XXX, XXY, XYY, XXYY, $\mathrm{XXXXY}, \mathrm{XX}$, and $\mathrm{XY}$ ). This unique neuroimaging sample allows an integrated analysis of sex and sex chromosome effects on cerebellar anatomy. We estimate allometric norms for the human cerebellum using a nonoverlapping "allometric sample" of 116 typically developing individuals (50 females). By spanning a narrow 2 year age band centered on the mean age of our core sample, this allometric sample allows us to derive reference cerebellar scaling norms in youth while limiting the potentially biasing effects of age-related anatomical covariation. These reference scaling norms are then used to define brain size-independent cerebellar changes in our core sample.

\section{Materials and Methods \\ Sample}

Our study includes a total of 417 participants (301 in the core sample and 116 in the allometric sample), with demographic and clinical characteristics detailed in Table 1. Participants with SCA were recruited through the National Institutes of Health (NIH) website and parent support groups. Inclusion criteria included X-/Y-supernumeracy, which had been confirmed by karyotype testing. Exclusion criteria included the following: history of head injury, neurological condition resulting in gross brain abnormalities, and mosaicism (determined by visualization of 50 metaphase spreads in peripheral blood). Typically developing individuals in both the core and allometric samples were singletons enrolled in longitudinal studies of typical brain development (Clinical trial reg. no. NCT00001246, clinicaltrials.gov; NIH Annual Report Number, ZIA MH002794-13; Giedd et al., 2015). Exclusion criteria included the following: use of psychiatric medication, enrollment in special education services, history of mental health treatment, or prior diagnosis of a medical condition that impacts the nervous system.

\section{Image acquisition and processing}

All structural magnetic resonance imaging brain scans were T1weighted images obtained on the same 1.5 T General Electric SIGNA scanner with contiguous $1.5 \mathrm{~mm}$ axial slices using a 3D spoiled gradient-recalled echo sequence with the following parameters for image acquisition: echo time, $5 \mathrm{~ms}$; repetition time, $24 \mathrm{~ms}$; flip angle, $45^{\circ}$; acquisition matrix, $256 \times 192$; number of excitations, 1 ; and field of view, $24 \mathrm{~cm}$.

Total brain volume measurements were acquired by submitting scans to the CIVET 1.1.10 pipeline for automated morphometric analysis (AdDab'bagh et al., 2006). Here, our measure of total brain volume includes 

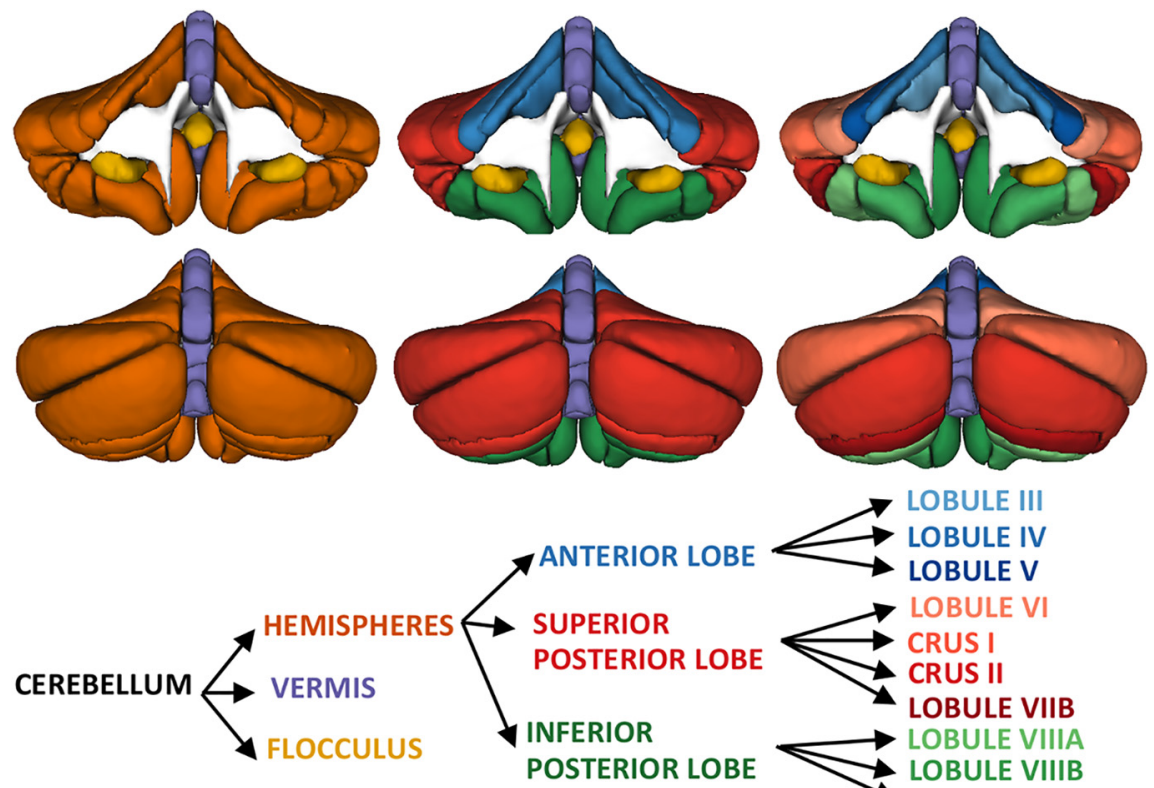

$\rightarrow$ LOBULE IV

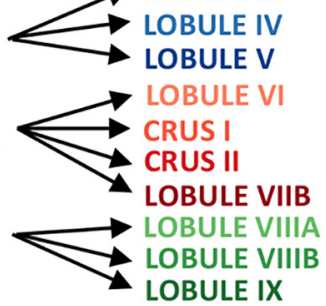

Figure 1. Cerebellar segmentation scheme. We used the recently developed the MAGeT Brain algorithm for multiatlas segmentation to profile cerebellar anatomy according to a nested scheme that fractionates total cerebellar volume into ever finer levels of spatial resolution spanning phylogenetic, lobar, and lobular divisions. These divisions are color coded on 3D surface renderings of the cerebellum shown from ventral (top row) and dorsal (bottom row) views, and these same color codes are used to distinguish cerebellar regions in Figures 3 and 4.

the combined estimates of total gray and white matter volume as calculated by CIVET using a validated neural net approach to voxel classification (Zijdenbos et al., 2002; Cocosco et al., 2003). To align our methodology with prior (predominantly phylogenetic) studies of cerebellar allometry (e.g., Barton and Harvey, 2000), we entered total brain volume in all analyses after first subtracting total cerebellar volume (estimated as detailed below). For notational clarity, we will refer to this adjusted index of total brain volume as aTBV.

All cerebellar measurements (Fig. 1) were automatically generated by a recently developed and well validated multiatlas segmentation algorithm-MAGeT Brain (Chakravarty et al., 2013; Park et al., 2014). This tool enabled us to fractionate TCbV into its three major functional/ phylogenetic subdivisions (hemispheres, vermis, flocculus) and then further subdivide the cerebellar hemispheres into their constituent lobes and lobules [anterior lobe (lobules III, IV, V), superior posterior lobe (lobule VI, Crus I, Crus II, lobule VIIB), and inferior posterior lobe (lobules VIIIA, VIIIB, IX); Fig. 1].

In brief, MAGeT Brain first used a set of five high-resolution in vivo atlases (three male, two female) to create automated cerebellar segmentations ("templates") for 21 randomly selected participants within our sample, providing a study-specific library of 105 segmentations ( 5 atlases $\times 21$ templates). The five reference atlases used by MAGeT Brain were generated by having two trained anatomists manually segment each of these five scans, blind to each other's ratings, using the naming conventions for cerebellar anatomy provided by Schmahmann et al. (2000) and further explained by Park et al. (2014). These conventions are fully described in detail in our previous work (Park et al., 2014). However, we summarize the procedure here for completion. The Schmahmann nomenclature for referring to cerebellar subregions provides a comprehensive and hierarchical consensusbased mapping of cerebellar lobules that is based on a systematic comparison of previous work (Schmahmann et al., 2000). The finest level of this anatomical hierarchy distinguishes 12 cerebellar lobules, with hemispheric and vermal (in brackets) counterparts, as follows: lobules I-VI, Crus I (VIIAf), Crus II (VIIAt), VIIB, VIIIA/B, IX, and X/flocculus (nodulus). These lobules can be further grouped into their respective lobes, which include the anterior (lobules I-V), superior posterior (lobules VI-VIIB), and inferior posterior (lobules VIIIA-IX) lobes, with corresponding hemispheric and vermal divisions as well. These regions can themselves be grouped into phylogenetic
LOBULE III

divisions, comprising the cerebellar hemispheres (hemispheric I-IX), vermis (vermal I-IX), and flocculonodular lobe (hemispheric and vermal X). Traditionally, lobules I-II are included in the anterior lobe; however, they are not present outside of the vermis. Major landmarks of note, as compiled by Schmahmann et al. (2000) and used in the manual labeling of MAGeT Brain reference atlases, include the primary, prepyramidal/prebiventer, and posterolateral fissures, which define lobar divisions across anterior/superior posterior, superior posterior/inferior posterior, and inferior posterior/flocculonodular lobes. These neuroanatomical definitions, and the anatomical variability captured by the five atlases, were then propagated onto the subject population through the template library to enhance segmentation accuracy through the registration pipeline. When compared with "gold standard" manual segmentation, MAGeT Brain exhibits high accuracy in the identification of the total cerebellum (mean $\kappa=0.925)$ and segmentation of individual lobules (mean $\kappa=0.731$; Park et al., 2014).

Each scan within our dataset was labeled using all 105 segmentations within the study-specific MAGeT Brain library, and the final segmentation for each scan was determined by a voxelwise majority vote. All raw scans and final segmentations in this analysis passed a quality-control screen for motion artifact and segmentation errors (respectively), as implemented by a single rater who was blinded to karyotype status.

Statistical modeling.

Participant characteristics. Participant characteristics were compared across karyotype groups using ANOVA $F$ tests and $\chi^{2}$ tests for continuous and categorical variables, respectively.

Sex and sex chromosome aneuploidy effects on raw cerebellar volumes. We calculated the mean volume of the cerebellum and its subdivisions in each karyotype group within our core sample (Fig. 2) and tested for a significant omnibus effect of group on each volume using $F$ tests. For cerebellar regions showing a statistically significant omnibus effect of group, we conducted post hoc $t$ tests to map pairwise volume differences between karyotype groups (Fig. 2). To facilitate the comparison of karyotype group effects across multiple cerebellar components, we also plotted observed cerebellar volume distributions in each karyotype group as an effect-size shift relative to the distribution observed in XY males (Fig. 3; with the effect size for the aTBV shift in each group also included for comparison). Effect sizes were calculated as (mean volume of XY group - mean volume of comparison group)/SD of $\mathrm{XY}$ group.

Normative allometry of the human cerebellum. We generated allometric scaling norms for the cerebellum by applying a classic log-log regression approach (Huxley, 1924) within the nonoverlapping allometric sample of 116 typically developing males and females. Under this approach, the scaling relationship of metric A relative to metric $\mathrm{B}$ is given by $\beta_{1}$ in the following equation:

$$
\log 10(\mathrm{~A})=\beta_{0}+\beta_{1} \log 10(\mathrm{~B}) .
$$

This formula permits a tractable linear model for estimating the nonlinear allometric relationship between cerebellar volumes and aTBV. The formula also facilitates interpretation of the scaling coefficient specifically, as follows: $\beta_{1}$ values significantly $<1$ indicate a hypoallometric scaling relationship, where A becomes proportionally smaller as B increases (or conversely, proportionally larger as B decreases). Conversely, $\beta_{1}$ values significantly $>1$ indicate a hyperallometric scaling relationship, where A becomes proportionally larger as B increases. $\beta_{1}$ values equivalent to 1 indicate an "isometric" scaling relationship where the proportional size of $A$ relative to $B$ is maintained across all values of $\mathrm{B}$. 


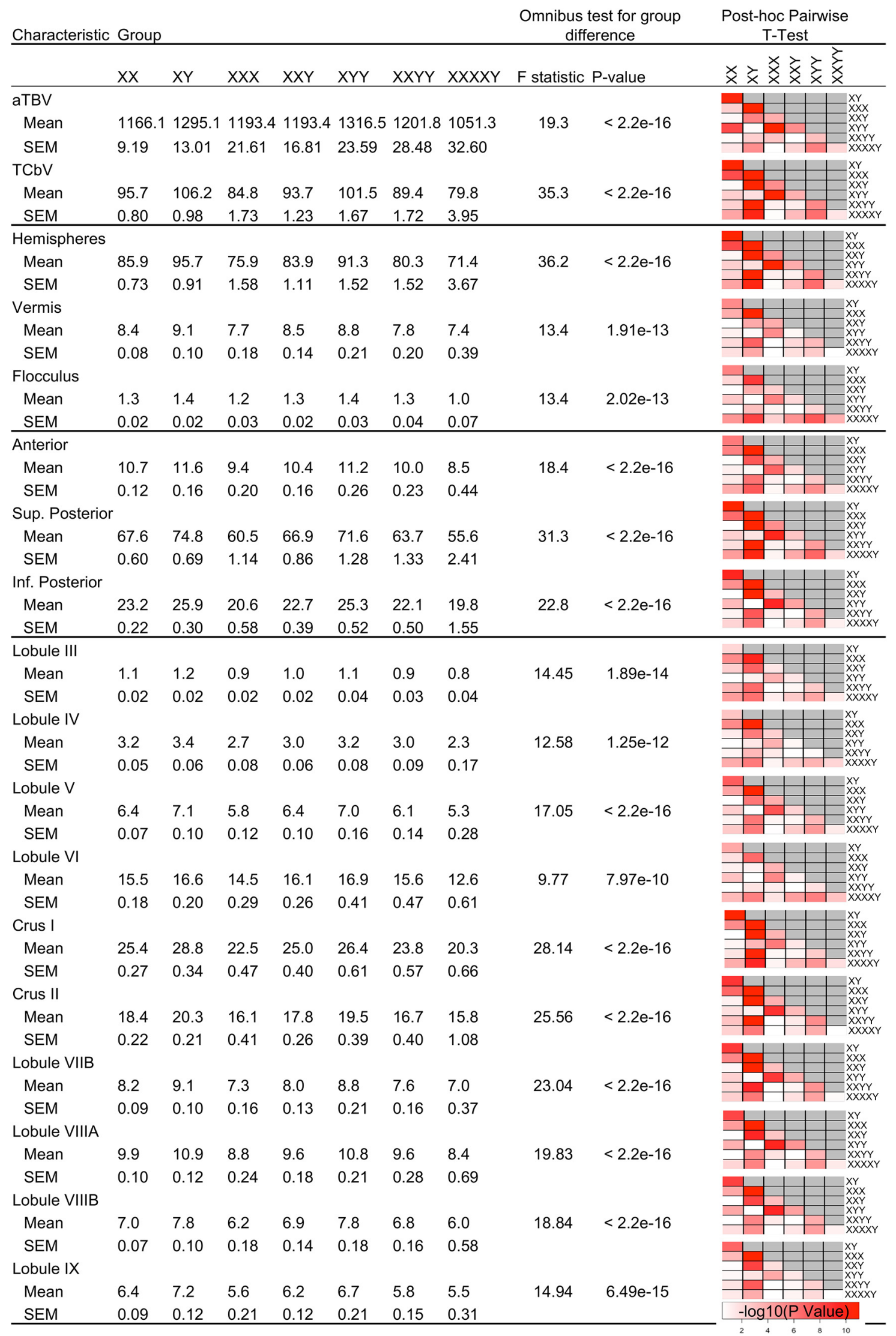

Figure 2. Global and regional cerebellar volumes in each group $\left(\mathrm{cm}^{3}\right)$ and tests for group differences. Mean (SEM) volumes are shown for all volumetric indices in each karyotype group within the core sample along with (1) results of an $F$ test for the omnibus effect of karyotype group on each volume and (2) a heat map of -log10 $p$ values for all unique pairwise $t$ tests for karyotype group differences in each volume. 
A

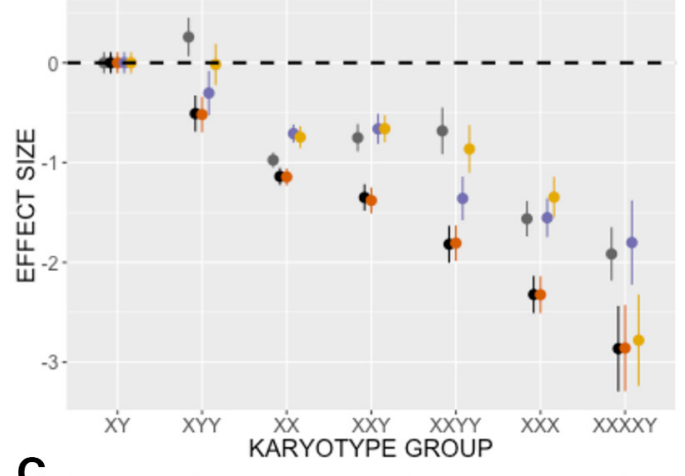

C
B

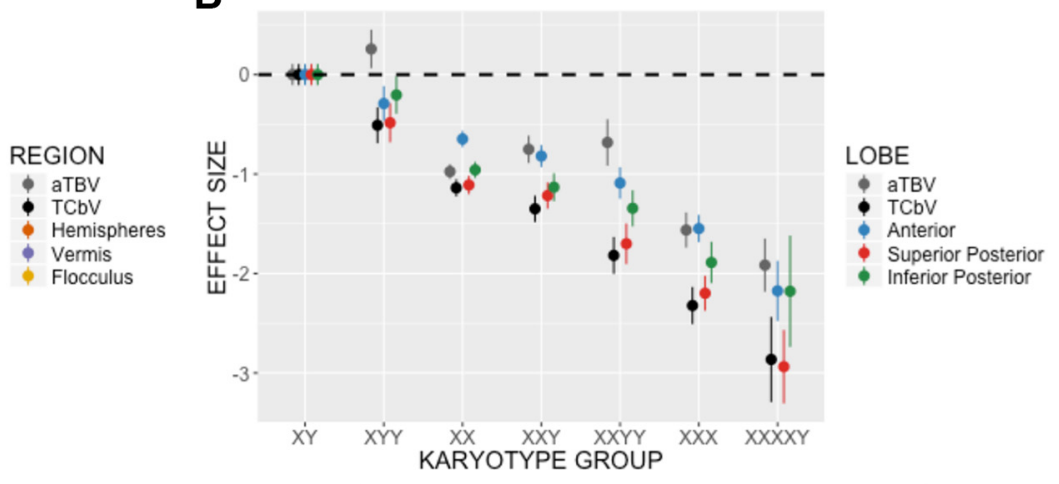

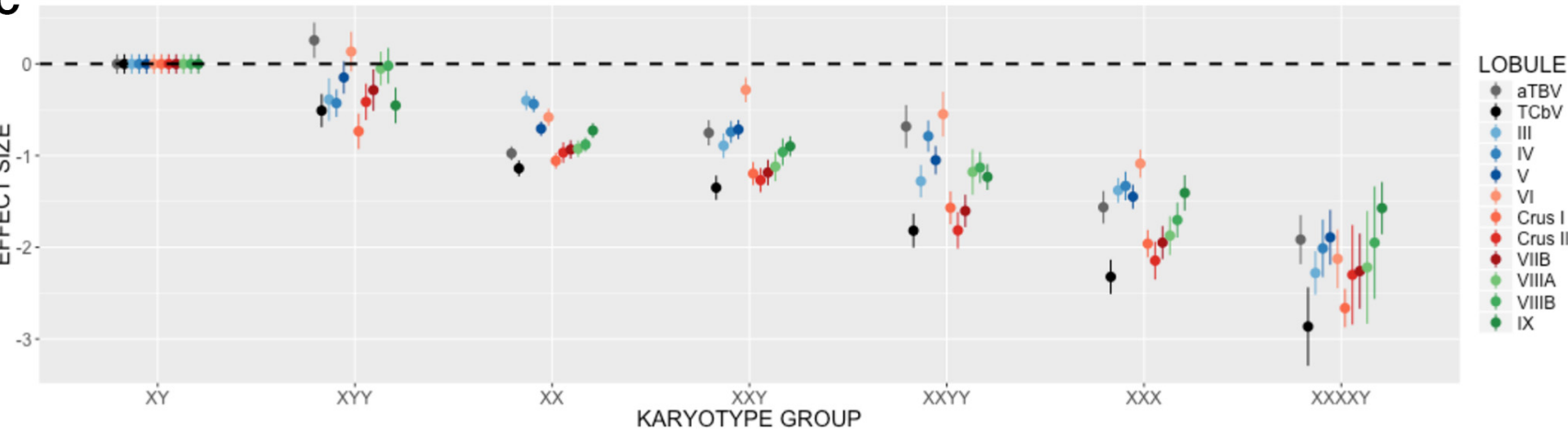

Figure 3. Point-range plots detailing cerebellar volume variation across the seven groups in our core sample. Mean volumes ( $\pm 95 \%$ confidence intervals) of all cerebellar volumes and aTBVs are shown in each karyotype group as effect size shifts relative to XY males as a common reference group. $\boldsymbol{A}-\boldsymbol{C}$, Effect sizes are plotted separately for phylogenetic $(\boldsymbol{A})$, lobar $(\boldsymbol{B})$, and lobular $(\boldsymbol{C})$ divisions using color codes that are identical to those in Figure 1.

To safeguard against falsely assuming equivalent models [in slope/ scaling coefficient $\left(\beta_{1}\right)$ and intercept $\left(\beta_{0}\right)$ ] for males and females, we used our log-log regression framework to sequentially test three general linear models of cerebellar allometry. We tested these three models in order of decreasing complexity and freedom for sex differences by following the below steps for each cerebellar volume (total cerebellar volume used as an example in the equations below).

First, we tested for evidence that males and females differ in the scaling coefficient itself, such that different allometric scaling principles hold for males and females $\left(\beta_{3}\right)$ :

$\log 10(\mathrm{TCbV})=\beta_{0}+\beta_{1}(\log 10(\mathrm{aTBV}))+\beta_{2}(\mathrm{SEX})$

$$
+\beta_{3}(\log 10(\mathrm{aTBV}) \times \mathrm{SEX}) .
$$

In the absence of evidence for a sex difference in scaling, we proceeded to the next lower-order model, which includes a single scaling relationship that applies in both sexes, while still allowing for a baseline sex difference (sex offset) in structure size at any given aTBV value, which is reflected in the following $\beta_{2}$ term:

$$
\log 10(\mathrm{TCbV}) \sim \beta_{0}+\beta_{1}(\log 10(\mathrm{aTBV}))+\beta_{2}(\mathrm{SEX}) .
$$

Finally, cerebellar regions that lacked significant sex differences in volume when controlling for aTBV were modeled according to the following equation:

$$
\log 10(\mathrm{TCbV}) \sim \beta_{0}+\beta_{1}(\log 10(\mathrm{aTBV})) .
$$

The coefficients, associated $p$ values, and full model $R^{2}$ values for the appropriate allometric models linking variation in regional cerebellar volume to aTBV are detailed in Table 2. Scaling coefficients are visualized across all cerebellar subregions in Figure 4. In addition, scaling relationships for five cerebellar subregions, which were selected to exemplify different modes of cerebellar allometry, are also shown as scatterplots with superimposed allometric fit lines in Figure 5.
Sex and SCA effects in the context of allometry. The allometric analyses above provided (1) statistical tests for brain size-independent sex differences in cerebellar volume among typically developing males and females, and (2) an estimated set of region-specific cerebellar scaling norms that could be used to test for brain size-independent effects of SCA on cerebellar volume. For all SCA groups within our core sample (other than the small group of five XXXXY individuals), we tested for differences between observed cerebellar volumes and those predicted by normative cerebellar allometry in the following manner. First, for each cerebellar volume, normative scaling expectations were defined according to the model (i.e., 2 vs 3 vs 4 above) selected by analysis within our typically developing allometric sample. Thus, in cerebellar regions where model 4 applied, observed cerebellar volumes in all SCA groups would be compared with predictions from a single regression line; whereas, in cerebellar regions where models 2 or 3 applied, observed cerebellar volumes in each SCA group would be compared with the specific predictions appropriate for its gonadal sex (i.e., XXX observations were compared with predictions for XX, and observed volumes in all other SCAs were compared with predictions for XY). Next, for all participants within our core sample, we calculated the deviation between their observed $\log 10$ cerebellar volumes and those that would be predicted given their aTBV and the appropriate allometric model. Finally, Wilcoxon rank-sum tests were used to compare distributions of these deviations between each SCA group and its appropriate gonadal control group within the core sample. For each volumetric measure, $p$ values from the Wilcoxon test were Bonferronicorrected to account for the five SCA group contrasts being conducted (Table 3).

Analysis of sex and sex chromosome aneuploidy effects using normalization and covariation to control for brain size. We also sought to directly compare the results of our allometric approach with those of the two prevailing methods used in an attempt to "control" for aTBV effects in neuroanatomical literature, as follows: (1) normalization and (2) covariation. In normalization, group differences in a cerebellar volume are 
Table 2. Normative scaling relationships between cerebellar volumes and aTBV

\begin{tabular}{|c|c|c|c|c|c|c|c|}
\hline \multirow[b]{2}{*}{ Structure } & \multicolumn{2}{|c|}{ Allometric scaling with aTBV } & \multicolumn{2}{|l|}{ Male offset } & \multicolumn{2}{|l|}{ Sex interaction } & \multirow[b]{2}{*}{$R^{2}$} \\
\hline & $\beta_{1}$-coefficient (SE) & $p($ for null coefficient $=1)$ & $\beta_{2}$-coefficient (SE) & $p$ & $\beta_{3}$-coefficient (SE) & $p$ & \\
\hline TCbV & $0.60(0.061)$ & $1.23 \mathrm{E}-09$ & $0.017(0.002)$ & 0.002 & & & 0.66 \\
\hline \multicolumn{8}{|l|}{ Regions } \\
\hline Hemispheres & $0.61(0.062)$ & $5.04 \mathrm{E}-09$ & $0.018(0.006)$ & 0.002 & & & 0.66 \\
\hline Vermis & $0.56(0.072)$ & $2.04 \mathrm{E}-08$ & & & & & 0.35 \\
\hline Flocculus & $0.39(0.100)$ & $1.86 \mathrm{E}-08$ & $0.032(0.009)$ & 0.001 & & & 0.38 \\
\hline \multicolumn{8}{|l|}{ Lobes } \\
\hline Anterior & $0.93(0.166)$ & 0.679 & $2.85(1.340)$ & 0.036 & $-0.47(0.220)^{*}$ & 0.036 & 0.36 \\
\hline Superior posterior & $0.53(0.064)$ & 4.97E-11 & $0.015(0.006)$ & 0.012 & & & 0.58 \\
\hline Inferior Posterior & $0.84(0.079)$ & 0.041 & $0.019(0.007)$ & 0.012 & & & 0.67 \\
\hline \multicolumn{8}{|l|}{ Lobules } \\
\hline Lobule III & $0.59(0.121)$ & 0.0011 & & & & & 0.17 \\
\hline Lobule IV & $0.61(0.126)$ & 0.0024 & & & & & 0.17 \\
\hline Lobule V & $0.72(0.087)$ & 0.0017 & & & & & 0.38 \\
\hline Lobule VI & $0.63(0.086)$ & 2.99E-05 & & & & & 0.32 \\
\hline Crusl & $0.66(0.072)$ & 8.47E-06 & & & & & 0.43 \\
\hline Crus II & $0.36(0.091)$ & $1.18 \mathrm{E}-10$ & $0.031(0.008)$ & $2.79 \mathrm{E}-04$ & & & 0.39 \\
\hline Lobule VIIB & $0.59(0.088)$ & 9.54E-06 & $0.022(0.008)$ & 0.006 & & & 0.51 \\
\hline Lobule VIIIA & $0.73(0.083)$ & 0.0016 & $0.021(0.008)$ & 0.008 & & & 0.61 \\
\hline Lobule VIIIB & $0.90(0.093)$ & 0.274 & $0.017(0.009)$ & 0.042 & & & 0.62 \\
\hline Lobule IX & $1.04(0.118)$ & 0.727 & & & & & 0.41 \\
\hline
\end{tabular}

Bold entries highlight regions with statistically significant evidence against the null hypotheses of isometric scaling and/or equivalent intercepts/slopes between males and females.

${ }^{*}$ Coefficient measures the difference in scaling coefficient between males and females. Thus, anterior lobe volume scales isometrically with aTBV in females (coefficient $=0.93$, no statistically significant difference from 1 ) but hypoallometrically with aTBV in males [coefficient $=0.46$ (i.e., $0.93-0.47$ ), significantly different from the female coefficient $(p=0.036)$ and from the isometric null coefficient of 1 ( $p=0.002)$ ].

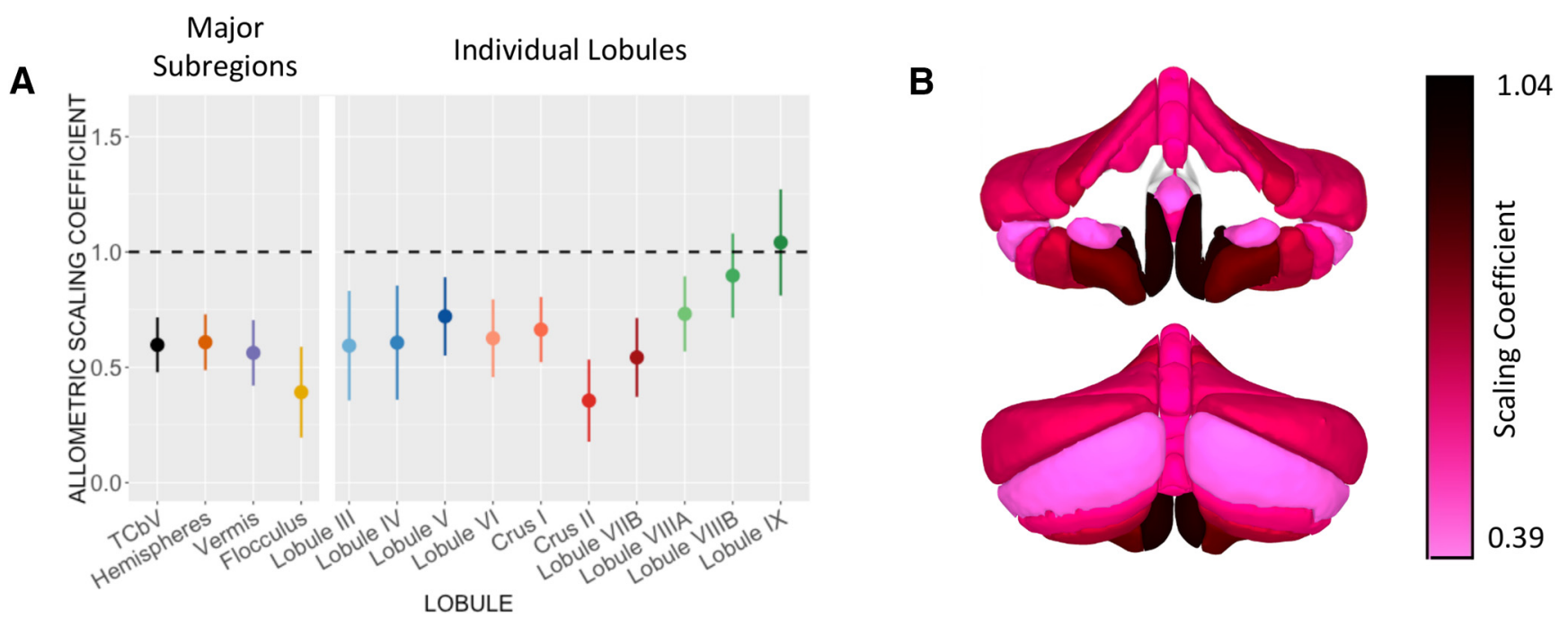

Figure 4. Normative allometry of cerebellar volume across lobules. $A$, A point-range plot showing the estimated scaling coefficient ( $\pm 95 \%$ confidence intervals) with aTBV for the TCbV, the three major phylogenetic subdivisions, and each cerebellar lobule. Color codes are identical to those in Figure 1. B, Cerebellar heat map with colors coding the allometric slope.

modeled after first re-expressing raw cerebellar volume as a fraction of aTBV (model 5 below, with TCbV as an example). In covariation, group differences in a cerebellar volume are modeled with aTBV included as a covariate (model 6 below).

$$
\begin{gathered}
\text { TCbV } / \mathrm{aTBV}=\beta_{0}+\beta_{1}(\text { GROUP }) \\
\mathrm{TCbV}=\beta_{0}+\beta_{1}(\text { GROUP })+\beta_{2}(\mathrm{aTBV}) .
\end{gathered}
$$

For assessing SCA effects within the core sample, these two models were run for each SCA group and its respective gonadal control group (i.e., GROUP was a binary categorical variable, and $\beta_{1}$ estimated the SCA control volumetric difference). For both of these models, $p$ values associated with GROUP effects were Bonferroni-corrected for each cerebellar volume to account for the five pairwise contrasts (one per SCA group) being conducted. To assess sex effects, models 5 and 6 were run within the allometric sample, where GROUP was a binary categorical variable and $\beta_{1}$ estimated the male-female volumetric difference.
All statistical analyses described above were performed using R software ( $\mathrm{R}$ Core Team, 2015), with use of add-on packages ggplot2, reshape2, and plotrix (Lemon, 2006; Wickham, 2007, 2009).

\section{Results}

Sex and sex chromosome aneuploidy effects on cerebellar volume

Global and regional cerebellar volumes all showed statistically significant variation across the seven distinct karyotype groups represented in our core sample of 301 individuals (Table 1, Figs. $2,3)$. With regard to normative sex differences, females had significantly smaller aTBVs, as well as smaller absolute global and regional cerebellar volumes than males. The effect size of volumetric sex differences varied greatly between cerebellar subregions. Specifically, the effect size of cerebellar volume reduction in females versus males was larger in the hemispheres than in the vermis and flocculus and, within the hemispheres, was largest in 

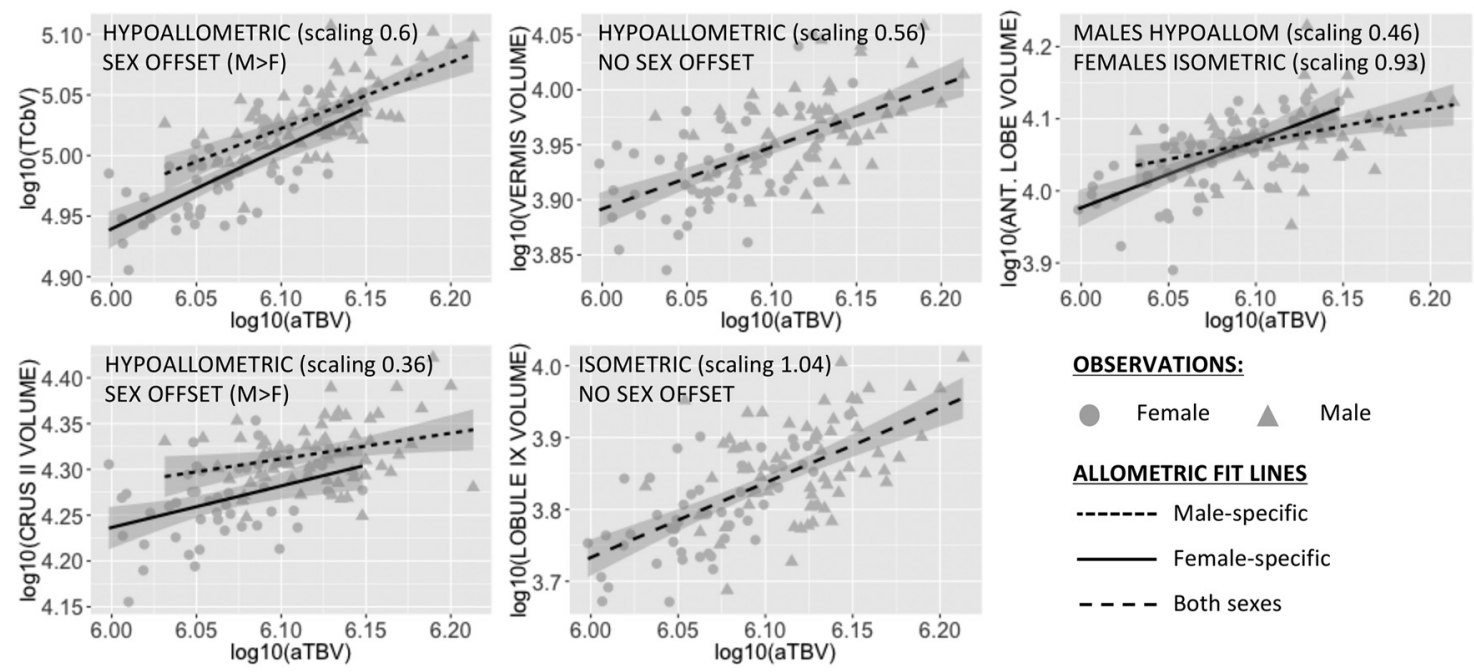

OBSERVATIONS:

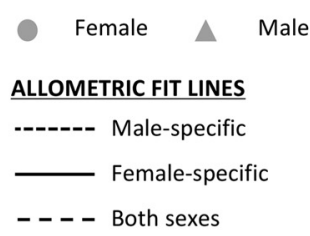

Figure 5. Normative cerebellar scaling. Scatter plots of volumetric data and best-fit scaling models for selected cerebellar regions. Gray points indicate volumetric observations for females (circles) and males (triangles) in the allometric sample. Superimposed lines show the best fit $\log -\log$ relationship between aTBVs and cerebellar volumes ( $\pm 95 \%$ confidence intervals). Sexes are modeled separately in regions with statistically significant sex differences in scaling or offset $(p<0.05)$. The cerebellum as a whole scales hypoallometrically with aTBV, and shows an aTBVindependent volume increase in males vs females. Note the diversity of scaling models across different cerebellar subregions. These plots show the reference fit lines used for "allometrically corrected" reanalysis of cerebellar anatomy in SCA.

Table 3. Allometrically corrected effects of sex and SCA on regional cerebellar anatomy

\begin{tabular}{|c|c|c|c|c|}
\hline \multirow[b]{3}{*}{ Volume } & \multicolumn{4}{|c|}{ Wilcoxon test $p$ values for group differences } \\
\hline & \multirow{2}{*}{$\frac{\text { Versus XX }}{X X X}$} & \multicolumn{3}{|l|}{ Versus XY } \\
\hline & & $X X Y$ & $X Y Y$ & XXYY \\
\hline $\mathrm{TCbV}$ & $<0.0001$ & $<0.0001$ & 0.0005 & $<0.0001$ \\
\hline Hemispheres & $<0.0001$ & $<0.0001$ & 0.0003 & $<0.0001$ \\
\hline Vermis & 0.0114 & 0.4309 & 0.1431 & 0.0001 \\
\hline Flocculus & 0.3950 & 0.0027 & 1.0000 & 0.0359 \\
\hline Anterior & 0.0679 & 0.0015 & 0.2028 & 0.0003 \\
\hline Superior posterior & 0.0003 & $<0.0001$ & 0.0043 & $<0.0001$ \\
\hline Inferior posterior & 0.0008 & $<0.0001$ & 0.0166 & $<0.0001$ \\
\hline Lobule III & 0.0571 & $<0.0001$ & 0.1780 & $<0.0001$ \\
\hline Lobule IV & 0.0079 & 0.0088 & 0.0136 & 0.0444 \\
\hline Lobule V & 0.0594 & 0.1884 & 0.7230 & 0.0025 \\
\hline Lobule VI & 1.0000 & 0.6716 & 1.0000 & 1.0000 \\
\hline Crus I & 0.0022 & $<0.0001$ & 0.0002 & $<0.0001$ \\
\hline Crus II & 0.0002 & $<0.0001$ & 0.0974 & $<0.0001$ \\
\hline Lobule VIIB & 0.0006 & $<0.0001$ & 0.0727 & $<0.0001$ \\
\hline Lobule VIIIA & 0.0003 & $<0.0001$ & 0.4884 & 0.0015 \\
\hline Lobule VIIIB & 0.0293 & 0.0096 & 0.5019 & 0.0039 \\
\hline Lobule IX & 0.1041 & 0.0212 & 0.0061 & 0.0013 \\
\hline
\end{tabular}

Table of Bonferroni-corrected $p$ values for observed cerebellar volume reductions in SCA groups relative to gonadal controls within the core sample after correction for aTBV using independently derived allometric norms. Bold values are statistically significant.

the superior posterior lobe. Lobular analysis revealed further intralobar heterogeneity in the effect sizes for sex differences in cerebellar volume: these effect sizes steadily mounted in the rostral transition from lobule X to Crus II, and showed a sharp reduction in magnitude between Crus I and lobule VI (Fig. 3).

Analysis of SCA effects revealed that X- and Y-chromosome additions were both associated with reductions in cerebellar volume, despite the presence of divergent X- and Y-chromosome effects on aTBV (decrease and increase, respectively; Figs. 2, 3). These data also established that (1) cerebellar volume reductions were greater in effect size with the addition of an $X$ - than a Y-chromosome (e.g., see comparison of both XYY and XXY groups relative to $\mathrm{XY}$ males; Figs. 2, 3), (2) increases in $\mathrm{X}$ - and
Y-chromosome count reduced cerebellar volumes in an additive manner (e.g., see comparison of the effect sizes for cerebellar volume loss across XXY, XYY, and XXYY groups relative to XY males; Figs. 2, 3), and (3) the effect size of SCA-induced cerebellar changes varied greatly across lobules in a manner that recapitulated the spatial distribution of normative sex differences on cerebellar volume.

\section{Normative allometry of the human cerebellum}

Next, to untangle the effects of sex and SCA on aTBV from observed sex and SCA effects on cerebellar anatomy, we used an independent sample of 116 typically developing individuals (Table 1) to quantify scaling relationships between cerebellar volumes and $\mathrm{TTBV}$ at the mean age of our core sample using a classic log-log regression approach (Huxley, 1924; Reardon et al., 2016). Total cerebellar volume showed hypoallometric scaling with aTBV in both sexes (Table 2, Fig. 4), implying that individuals with a larger aTBV have proportionally smaller TCbVs, but also showed an additional sex offset such that the mean TCbV was significantly larger in males than in females for any given aTBV. The volumes of the three major cerebellar subdivisions all scaled hypoallometrically with aTBV but to differing extents (Table 2, Fig. 4): the flocculus exhibited the most pronounced hypoallometric scaling with aTBV, followed by the vermis and then the hemispheres (scaling coefficients, 0.39, 0.56, and 0.61, respectively). The significant sex offset apparent for TCbV was also evident for the volume of the cerebellar hemispheres and flocculus, while the apparent sex difference in vermal volume was explained by aTBV variation alone (Table 3 ).

Individual cerebellar regions varied greatly in their scaling relationships with aTBV (Table 2, Fig. 4), which ranged from profound hypoallometry (scaling coefficient significantly $<1$, indicating a lack of proportionate volume increase with mounting aTBV), to isometry (scaling coefficient of 1 , indicating proportionate volume increase with mounting aTBV). At the lobar level, cerebellar volume scaling with aTBV was isometric in the inferior posterior lobe, hypoallometric in the superior posterior lobe, and sexually dimorphic in the anterior lobe (isometric in females vs hypoallometric in males). Lobular analysis revealed that scaling 
NORMALIZATION

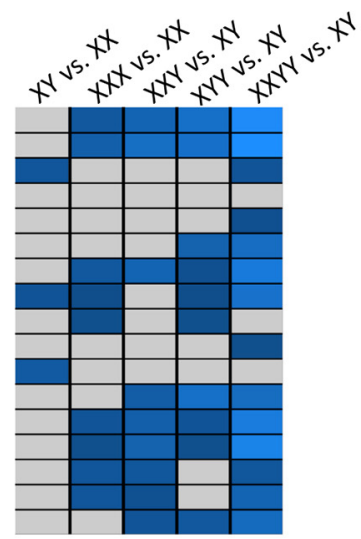

COVARIATION

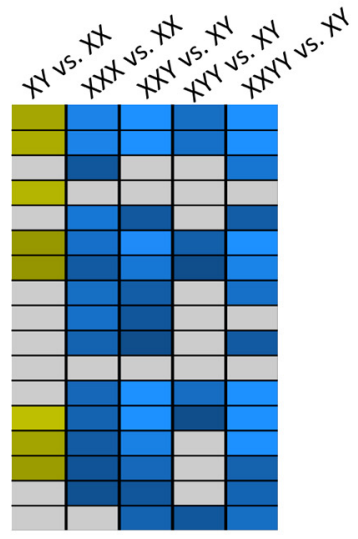

$\underline{\text { ALLOMETRY }}$

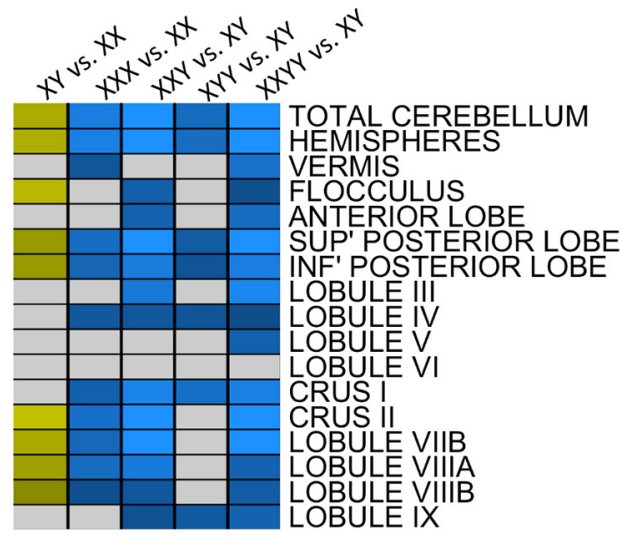

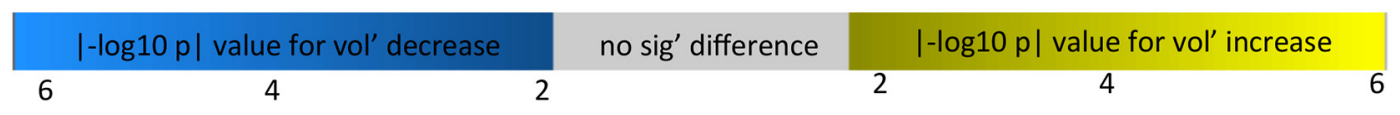

Figure 6. Comparison of pairwise group differences in cerebellar volumes across methods for accounting for aTBV. Heat maps show $p$ values for significant volume differences between karyotype groups for multiple measures of cerebellar volume. Each heat map refers to a different method of controlling for brain size effects. $p$ values are shown on a $-\log 10$ scale, with more intense colors representing smaller $p$ values. Gray cells denote pairwise contrasts that are not statistically significant (Bonferroni-corrected, $p>0.05$ ). All significant contrasts involve volume reductions.

with aTBV was isometric for the two most caudal lobules (VIIIB, IX) but became increasingly hypoallometric moving rostrally toward Crus II, the most profoundly hypoallometric of all cerebellar lobules. There was a sharp reduction in the magnitude of lobular hypoallometry moving rostrally beyond Crus II: Crus I and lobules VI through III all showed significantly hypoallometric scaling with aTBV but to a milder degree than in Crus II. For the cerebellum as a whole, and illustrative cerebellar subdivisions, Figure 5 plots volumetric data and estimated regression models for normative scaling within the allometric sample.

\section{Sex and sex chromosome aneuploidy effects in the context of allometry}

Analysis of cerebellar scaling within our normative allometric sample (Table 2) revealed that the widespread sex differences evident for measures of raw cerebellar volume within the core sample (Figs. 2, 3) can be decomposed into a set of aTBVindependent sex differences (greater volume in males than females for total cerebellum | flocculus, hemispheres |Crus II, and lobules VIIB, VIIIA, and VIIIB), and sex differences in cerebellar volume that are in fact explained by sex differences in aTBV (vermis | lobules III through Crus I). The anterior cerebellar lobe as a whole (i.e., the sum of volumes for lobules III, IV, and V) is notable for showing normative sex differences that vary with aTBV due to sex differences in the scaling of anterior lobe volume with aTBV (males relatively larger than females at low aTBVs but vice versa at higher aTBVs).

We used the allometric norms defined above to test whether SCA effects on cerebellar volume observed within our core sample represented (1) distortions of cerebellar size relative to aTBV or (2) differences that were fully concordant with the large effectsize influence of SCA on aTBV. For each individual within our core sample, observed cerebellar volumes were expressed as differences from the allometric expectations defined in our nonoverlapping sample of controls. These differences were used to test for allometrically corrected group differences in regional cerebellar volume within our core sample between each SCA group and its respective gonadal control group (Table 3 ). We found that supernumerary X- and Y-chromosomes both cause a disproportionate reduction of total cerebellar volume relative to their observed effects on aTBV. These convergent and disproportionate effects of X-and Y-chromosome count on total cerebellar volume were also evident for the hemispheres taken as a whole, and for lobule IV and Crus I within the hemispheres. In contrast, for Crus II and lobules VIIB, VIIIA, and VIIIB, disproportionate volume reductions were evident only with the addition of an extra $\mathrm{X}$-chromosome, but not an extra Y-chromosome, after correction for multiple comparisons. Finally, the relative volume of lobule VI appeared to be insensitive to variations in $\mathrm{X}$ - and Y-chromosome count.

To highlight the consequences of choosing different methodologies for the analysis of sex and SCA effects on cerebellar anatomy, Figure 6 summarizes the group differences in cerebellar volume that are identified by each of the following three analytic approaches for "control" of aTBV effects: (1) analysis of cerebellar volume normalized for aTBV, (2) analysis of cerebellar volume covarying for aTBV, and (3) analysis of observed cerebellar volumes compared with allometric expectations. Group differences are indexed using $-\log 10 p$ values as the single statistical metric that is common to all three methods for assessing "aTBVcorrected" pairwise group differences in anatomy.

Comparison across the methods used to test for sex and SCA effects on cerebellar anatomy in our study (Fig. 6) identified several instances in which "classical" methods for aTBV correction, which are unable to account for nonlinear cerebellar scaling with aTBV, distort group differences in cerebellar anatomy. Specifically, we found that conventional methods for aTBV control can both obscure (e.g., the failure of covariation to detect relative reduction of flocculus volume in XXY vs XY males), and exaggerate (e.g., false detection of statistically significant reductions of Crus II volume in XYY vs XY males by both covariation and normalization) the sex and SCA effects on regional cerebellar anatomy that are revealed by the more biologically valid method of "allometric correction" based on knowledge of scaling norms. 


\section{Discussion}

\section{Sex and sex chromosome aneuploidy effects on raw} cerebellar volumes

Our findings refine and extend knowledge of sex and SCA effects on raw cerebellar volume in humans. With regard to normative sex differences, we show that the previously recognized malefemale difference in total cerebellar volume (Tiemeier et al., 2010; Brain Development Cooperative Group, 2012; Wierenga et al., 2014) is not evenly distributed across cerebellar subregions (Figs. 2,3 ). With regard to SCA effects, we build on a prior report of reduced TCbV in XXY vs XY males (Giedd et al., 2007) by showing that comparable X-chromosome effects on cerebellar volume are also apparent in a female gonadal context (i.e., XXX vs XX). We further establish that Y-chromosome aneuploidy also causes reductions in raw cerebellar volume, which operate additively with X-chromosome effects. Furthermore, the magnitude of SCA effects on cerebellar volume varies greatly between different components of the cerebellum, echoing the spatial gradients seen for normative sex differences in cerebellar volume.

While the above findings bring a new level of granularity to our understanding of sex and SCA effects on cerebellar anatomy in humans, our study stresses the critical need to examine such effects in the context of brain allometry.

\section{Normative allometry of the human cerebellum}

The substantial impact of sex and SCA on overall brain size (Figs. $2,3)$ makes cerebellar allometry an essential framework for the interpretation of observed sex and SCA effects on cerebellar anatomy. In building this allometric framework, we discovered that normative scaling relationships between cerebellar volume and aTBV in humans are nonlinear and regionally heterogeneous. These observations carry evolutionary and developmental significance in their own right.

First, for the cerebellum as a whole and its three major phylogenetic subdivisions, we find patterns of scaling with aTBV that recapitulate previously reported patterns of cerebellar scaling across species. Specifically, (1) we confirm a hypoallometric scaling of TCbV with aTBV in humans (Charvet et al., 2013), which mirrors the hypoallometric scaling relationship between cerebellar volume and brain size across species (Clark et al., 2001); and (2) for the hemispheres, vermis, and flocculus, we find that cerebellar regions with earlier emergence in evolution and development (Larsell, 1947), lesser expansion in humans versus other primates (MacLeod et al., 2003), and more pronounced hypoallometric scaling with brain size within primate taxa (MacLeod et al., 2003) show more pronounced hypoallometric scaling with aTBV in humans (i.e., flocculus hypoallometry $>$ vermis $>$ hemispheres). Conversely, within the hemispheres, we observe a clear disjunction between interspecific and intraspecific patterns of cerebellar scaling. For example, the most hypoallometric of cerebellar lobules in our study-Crus II-is notable for having undergone the greatest relative expansion in the human lineage (Balsters et al., 2010). Collectively, these observations suggest that the long-debated degree of alignment between interspecific and intraspecific patterns of brain scaling (Finlay and Darlington, 1995; Barton and Harvey, 2000) not only varies across different taxonomic granularities (Willemet, 2012), but also across different anatomical granularities.

Second, we discover that the dramatic spatial complexity of human cerebellar allometry features gradual gradients (in the rostral transition between lobule IX and Crus II) as well as sudden “jumps" (between Crus II and I). These findings underline that the mechanisms governing coregulated growth between the cerebellum and other brain regions are regionally specific, motivating further research into the mechanisms that might underlie this variegation. For example, developmental biology identifies several aspects of early cerebellar patterning that would provide plausible and testable mechanisms for both gradual (e.g., spatiotemporally graded expression of midbrain transcription factors) and sudden (e.g., lineage-specific expansion and migration of different cerebellar cell types within lobular boundaries) spatial shifts in allometry (Leto et al., 2016).

Third, the mechanisms governing cerebellar allometry appear to be sexually dimorphic in the anterior lobe, such that size variation in the region is relatively "uncoupled" from brain size among males compared with females. This finding requires replication, but could potentially index sex differences in functional relatedness between this cerebellar region and other brain systems. To date, there are no spatially fine-grained studies of sex differences in cerebellar connectivity with other brain regions (Ingalhalikar et al., 2014).

\section{Sex and sex chromosome aneuploidy effects in the context of allometry}

Models of normative cerebellar allometry also critically reframe conclusions regarding the impact of sex and SCA on cerebellar anatomy. Through allometric analysis, the flocculus, Crus II, and lobules VIIB to VIIIB emerge as specific cerebellar regions where the presence of greater volume in typically developing males versus females outstrips any differences that could be accounted for by effects of brain size alone. Diverse lines of evidence have independently implicated these cerebellar subregions in the biology of sex-biased neurodevelopmental disorders, such as autism spectrum disorder and attention deficit hyperactivity disorder (Stoodley, 2016), making further study of their sexually dimorphic development, structure, and function a priority for future translational research.

Reference to allometric norms also establishes that observed reductions of TCbV and cerebellar hemisphere volume in SCA are disproportionate to changes in aTBV. The capacity of increases in both $\mathrm{X}$ - and $\mathrm{Y}$-chromosome count to cause significant reductions in these volumes points toward a potential causal role of the few genes that are shared by both chromosomes, including (1) pseudoautosomal region (PAR) genes (Otto et al., 2011) and/or (2) the small set of X-Y gene pairs that have persisted as homologs outside the PAR (Bellott et al., 2014). Alternatively, the disproportionate loss of cerebellar volume across diverse SCAs may reflect a more general vulnerability of the cerebellum to genetic "insults" during early development (Ellegood et al., 2015). A speculative hypothesis under this alternative model is that vulnerability of the cerebellum to SCA reflects an intersection between the special sensitivity of large and rapidly dividing cerebellar Purkinje cells to proteomic/hypoxia stress (Hekman and Gomez, 2015) and the demonstrated capacity of major genetic copy number variations to induce these stress states across multiple cellular systems (Sheltzer et al., 2012). From a functional perspective, it is striking that lobule IV and Crus I are the two cerebellar subregions that most clearly show convergent effects of increasing $\mathrm{X}$ - and $\mathrm{Y}$-chromosome count. The apparent vulnerability of these regions to X-/Y-chromosome effects may have relevance for observed clinical features of SCA given that lobule IV and Crus I have been linked to motor control and languageprocessing tasks (Stoodley and Schmahmann, 2009; Bostan et al., 2013; Riedel et al., 2015), which appear to be impaired across multiple SCAs (Lee et al., 2012; Hong and Reiss, 2014). 
Within the cerebellum, Crus II and lobules VIIB to VIIIB were notable for their differential sensitivity to X-and Y-chromosomes. Specifically, the presence of a supernumerary X-chromosome caused significantly disproportionate decreases in the volume of these regions, whereas the presence of a supernumerary Y-chromosome did not. Given that the proportional volume of these regions is also smaller in typically developing XX females compared with typically developing XY males, our findings are consistent with the hypothesis that sex chromosome complement may contribute to normative sex differences in the relative size of Crus II and lobules VIIB to VIIIB.

Finally, our reanalysis of sex and SCA effects using the two dominant methods for "controlling" aTBV effects, both of which assume linear scaling between local and global brain anatomy, empirically demonstrates the methodological dangers of ignoring allometry. We are able to replicate the findings of past studies that have used these nonallometric methods when studying sex differences in cerebellar anatomy (Sowell et al., 2002; Fan et al., 2010) and further show that these findings arise as a predictable artifactual consequence of failing to control for nonlinear relationships between cerebellar and brain volumes.

\section{Limitations and future directions}

Our findings should be considered in light of several study limitations. First, we focused on the main effects of sex and SCA, but, once sufficiently large cohorts of participants with SCA are available, it will become possible to test for dynamic interactions between age and sex/SCA in predicting cerebellar anatomy. Related to this, we constructed allometric norms for the cerebellum within a narrow age window at the mean age of our core sample (to limit age-mediated covariation between aTBVs and cerebellar volumes). A priority for future work will be leveraging large-scale normative samples to assess the developmental stability of allometry in the human brain. Second, despite using state-of-the-art techniques for automated cerebellar segmentation (Park et al., 2014), the resulting volume estimates collapse across different tissue classes and cell types. Future access to spatiotemporally comprehensive maps of molecular and cellular phenotypes in human cerebellar development (Miller et al., 2014) could potentially identify candidate genetic and/or histological underpinnings for the allometric norms that we define in the current report. Third, the distributive nature of cognitive functions and the complex topography of cerebellar connectivity with other brain regions (Buckner et al., 2011; Riedel et al., 2015) suggest that realistically appraising the relevance of our findings for sex and SCA effects on behavior will require the integration of systems-level information regarding the coordination of cerebellar changes with those throughout other brain regions (Raznahan et al., 2016; Reardon et al., 2016).

\section{References}

Ad-Dab'bagh Y, Einarson D, Lyttelton O, Muehlboeck S, Mok K, Ivanov O, Vincent R, Lepage C, Lerch J, Fombonne E, Evans A (2006) The CIVET image-processing environment: a fully automated comprehensive pipeline for anatomical neuroimaging research. Paper presented at the 12th Annual Meeting of the Organization for Human Brain Mapping, Florence, Italy, June.

Arnold AP (2014) Conceptual frameworks and mouse models for studying sex differences in physiology and disease: why compensation changes the game. Exp Neurol 259:2-9. CrossRef Medline

Balsters JH, Cussans E, Diedrichsen J, Phillips KA, Preuss TM, Rilling JK, Ramnani N (2010) Evolution of the cerebellar cortex: the selective expansion of prefrontal-projecting cerebellar lobules. Neuroimage 49: 2045-2052. CrossRef Medline
Barton RA, Harvey PH (2000) Mosaic evolution of brain structure in mammals. Nature 405:1055-1058. CrossRef Medline

Bellott DW, Hughes JF, Skaletsky H, Brown LG, Pyntikova T, Cho TJ, Koutseva N, Zaghlul S, Graves T, Rock S, Kremitzki C, Fulton RS, Dugan S, Ding Y, Morton D, Khan Z, Lewis L, Buhay C, Wang Q, Watt J, et al (2014) Mammalian Y chromosomes retain widely expressed dosagesensitive regulators. Nature 508:494-499. CrossRef Medline

Bostan AC, Dum RP, Strick PL (2013) Cerebellar networks with the cerebral cortex and basal ganglia. Trends Cogn Sci 17:241-254. CrossRef Medline

Brain Development Cooperative Group (2012) Total and regional brain volumes in a population-based normative sample from 4 to 18 years: the NIH MRI Study of Normal Brain Development. Cereb Cortex 22:1-12. CrossRef Medline

Buckner RL, Krienen FM, Castellanos A, Diaz JC, Yeo BT (2011) The organization of the human cerebellum estimated by intrinsic functional connectivity. J Neurophysiol 106:2322-2345. CrossRef Medline

Charvet CJ, Darlington RB, Finlay BL (2013) Variation in human brains may facilitate evolutionary change toward a limited range of phenotypes. Brain Behav Evol 81:74-85. CrossRef Medline

Clark DA, Mitra PP, Wang SS (2001) Scalable architecture in mammalian brains. Nature 411:189-193. CrossRef Medline

Cocosco CA, Zijdenbos AP, Evans AC (2003) A fully automatic and robust brain MRI tissue classification method. Med Image Anal 7:513-527. CrossRef Medline

Corre C, Friedel M, Vousden DA, Metcalf A, Spring S, Qiu LR, Lerch JP, Palmert MR (2016) Separate effects of sex hormones and sex chromosomes on brain structure and function revealed by high-resolution magnetic resonance imaging and spatial navigation assessment of the Four Core Genotype mouse model. Brain Struct Funct 221:997-1016. CrossRef Medline

Ellegood J, Anagnostou E, Babineau BA, Crawley JN, Lin L, Genestine M, DiCicco-Bloom E, Lai JK, Foster JA, Peñagarikano O, Geschwind DH, Pacey LK, Hampson DR, Laliberté CL, Mills AA, Tam E, Osborne LR, Kouser M, Espinosa-Becerra F, Xuan Z, et al (2015) Clustering autism: using neuroanatomical differences in 26 mouse models to gain insight into the heterogeneity. Mol Psychiatry 20:118-125. CrossRef Medline

Fan L, Tang Y, Sun B, Gong G, Chen ZJ, Lin X, Yu T, Li Z, Evans AC, Liu S (2010) Sexual dimorphism and asymmetry in human cerebellum: an MRI-based morphometric study. Brain Res 1353:60-73. CrossRef Medline

Finlay BL, Darlington RB (1995) Linked regularities in the development and evolution of mammalian brains. Science 268:1578-1584. CrossRef Medline

Giedd JN, Snell JW, Lange N, Rajapakse JC, Casey BJ, Kozuch PL, Vaituzis AC, Vauss YC, Hamburger SD, Kaysen D, Rapoport JL (1996) Quantitative magnetic resonance imaging of human brain development: ages 4-18. Cereb Cortex 6:551-560. CrossRef Medline

Giedd JN, Clasen LS, Wallace GL, Lenroot RK, Lerch JP, Wells EM, Blumenthal JD, Nelson JE, Tossell JW, Stayer C, Evans AC, Samango-Sprouse CA (2007) XXY (Klinefelter Syndrome): a pediatric quantitative brain magnetic resonance imaging case-control study. Pediatrics 119:e232-e240. CrossRef Medline

Giedd JN, Raznahan A, Mills KL, Lenroot RK (2012) Review: magnetic resonance imaging of male/female differences in human adolescent brain anatomy. Biol Sex Differ 3:19. CrossRef Medline

Giedd JN, Raznahan A, Alexander-Bloch A, Schmitt E, Gogtay N, Rapoport JL (2015) Child psychiatry branch of the National Institute of Mental Health longitudinal structural magnetic resonance imaging study of human brain development. Neuropsychopharmacology 40:43-49. CrossRef Medline

Gur RC, Gunning-Dixon FM, Turetsky BI, Bilker WB, Gur RE (2002) Brain region and sex differences in age association with brain volume: a quantitative MRI study of healthy young adults. Am J Geriatr Psychiatry 10: 72-80. CrossRef Medline

Hekman KE, Gomez CM (2015) The autosomal dominant spinocerebellar ataxias: emerging mechanistic themes suggest pervasive Purkinje cell vulnerability. J Neurol Neurosurg Psychiatry 86:554-561. CrossRef Medline

Hong DS, Reiss AL (2014) Cognitive and neurological aspects of sex chromosome aneuploidies. Lancet Neurol 13:306-318. CrossRef Medline

Huxley J (1924) Constant differential growth-ratios and their significance. Nature 114:895-896. CrossRef

Ingalhalikar M, Smith A, Parker D, Satterthwaite TD, Elliott MA, Ruparel K, 
Hakonarson H, Gur RE, Gur RC, Verma R (2014) Sex differences in the structural connectome of the human brain. Proc Natl Acad Sci U S A 111:823-828. CrossRef Medline

Larsell O (1947) The development of the cerebellum in man in relation to its comparative anatomy. J Comp Neurol 87:85-129. CrossRef Medline

Lee NR, Wallace GL, Adeyemi EI, Lopez KC, Blumenthal JD, Clasen LS, Giedd JN (2012) Dosage effects of X and Y chromosomes on language and social functioning in children with supernumerary sex chromosome aneuploidies: implications for idiopathic language impairment and autism spectrum disorders. J Child Psychol Psychiatry 53:1072-1081. CrossRef Medline

Legué E, Riedel E, Joyner AL (2015) Clonal analysis reveals granule cell behaviors and compartmentalization that determine the folded morphology of the cerebellum. Development 142:1661-1671. CrossRef Medline

Lemon J (2006) Plotrix: a package in the red light district of R. R-News $6: 8-12$.

Leonard CM, Towler S, Welcome S, Halderman LK, Otto R, Eckert MA, Chiarello C (2008) Size matters: cerebral volume influences sex differences in neuroanatomy. Cereb Cortex 18:2920-2931. CrossRef Medline

Leto K, Arancillo M, Becker EB, Buffo A, Chiang C, Ding B, Dobyns WB, Dusart I, Haldipur P, Hatten ME, Hoshino M, Joyner AL, Kano M, Kilpatrick DL, Koibuchi N, Marino S, Martinez S, Millen KJ, Millner TO, Miyata T, et al (2016) Consensus paper: cerebellar development. Cerebellum 15:789-828. CrossRef Medline

MacLeod CE, Zilles K, Schleicher A, Rilling JK, Gibson KR (2003) Expansion of the neocerebellum in Hominoidea. J Hum Evol 44:401-429. CrossRef Medline

Chakravarty MM, Steadman P, van Eede MC, Calcott RD, Gu V, Shaw P, Raznahan A, Louis Collins DL, Lerch JP (2013) Performing labelfusion-based segmentation using multiple automatically generated templates. Hum Brain Mapp 34:2635-2654. CrossRef Medline

Miller JA, Ding SL, Sunkin SM, Smith KA, Ng L, Szafer A, Ebbert A, Riley ZL, Royall JJ, Aiona K, Arnold JM, Bennet C, Bertagnolli D, Brouner K, Butler S, Caldejon S, Carey A, Cuhaciyan C, Dalley RA, Dee N, et al (2014) Transcriptional landscape of the prenatal human brain. Nature 508:199206. CrossRef Medline

Otto SP, Pannell JR, Peichel CL, Ashman TL, Charlesworth D, Chippindale AK, Delph LF, Guerrero RF, Scarpino SV, McAllister BF (2011) About PAR: the distinct evolutionary dynamics of the pseudoautosomal region. Trends Genet 27:358-367. CrossRef Medline

Park MT, Pipitone J, Baer LH, Winterburn JL, Shah Y, Chavez S, Schira MM, Lobaugh NJ, Lerch JP, Voineskos AN, Chakravarty MM (2014) Derivation of high-resolution MRI atlases of the human cerebellum at 3T and segmentation using multiple automatically generated templates. Neuroimage 95:217-231. CrossRef Medline

R Core Team (2015) R: a language and environment for statistical computing. Vienna, Austria: R Foundation for Statistical Computing.

Raznahan A, Lee Y, Stidd R, Long R, Greenstein D, Clasen L, Addington A, Gogtay N, Rapoport JL, Giedd JN (2010) Longitudinally mapping the influence of sex and androgen signaling on the dynamics of human cortical maturation in adolescence. Proc Natl Acad Sci U S A 107:1698816993. CrossRef Medline

Raznahan A, Lee NR, Greenstein D, Wallace GL, Blumenthal JD, Clasen LS, Giedd JN (2016) Globally divergent but locally convergent X- and
Y-chromosome influences on cortical development. Cereb Cortex 26:7079. CrossRef Medline

Reardon PK, Clasen L, Giedd JN, Blumenthal J, Lerch JP, Chakravarty MM, Raznahan A (2016) An allometric analysis of sex and sex chromosome dosage effects on subcortical anatomy in humans. J Neurosci 36:24382448. CrossRef Medline

Riedel MC, Ray KL, Dick AS, Sutherland MT, Hernandez Z, Fox PM, Eickhoff SB, Fox PT, Laird AR (2015) Meta-analytic connectivity and behavioral parcellation of the human cerebellum. Neuroimage 117:327-342. CrossRef Medline

Roalf DR, Gur RE, Ruparel K, Calkins ME, Satterthwaite TD, Bilker WB, Hakonarson H, Harris LJ, Gur RC (2014) Within-individual variability in neurocognitive performance: age- and sex-related differences in children and youths from ages 8 to 21 . Neuropsychology 28:506-518. CrossRef Medline

Rutter M, Caspi A, Moffitt TE (2003) Using sex differences in psychopathology to study causal mechanisms: unifying issues and research strategies. J Child Psychol Psychiatry 44:1092-1115. CrossRef Medline

Schmahmann JD, Doyon J, Toga A, Petrides M, Evans A (2000) MRI atlas of the human cerebellum. San Diego: Academic.

Sheltzer JM, Torres EM, Dunham MJ, Amon A (2012) Transcriptional consequences of aneuploidy. Proc Natl Acad Sci U S A 109:12644-12649. CrossRef Medline

Sowell ER, Trauner DA, Gamst A, Jernigan TL (2002) Development of cortical and subcortical brain structures in childhood and adolescence: a structural MRI study. Dev Med Child Neurol 44:4-16. CrossRef Medline

Sowell ER, Peterson BS, Thompson PM, Welcome SE, Henkenius AL, Toga AW (2003) Mapping cortical change across the human life span. Nat Neurosci 6:309-315. CrossRef

Stoodley CJ (2016) The cerebellum and neurodevelopmental disorders. Cerebellum 15:34-37. CrossRef Medline

Stoodley CJ, Schmahmann JD (2009) Functional topography in the human cerebellum: a meta-analysis of neuroimaging studies. Neuroimage 44: 489-501. CrossRef Medline

Strick PL, Dum RP, Fiez JA (2009) Cerebellum and nonmotor function. Annu Rev Neurosci 32:413-434. CrossRef Medline

Sudarov A, Joyner AL (2007) Cerebellum morphogenesis: the foliation pattern is orchestrated by multi-cellular anchoring centers. Neural Dev 2:26. CrossRef Medline

Tiemeier H, Lenroot RK, Greenstein DK, Tran L, Pierson R, Giedd JN (2010) Cerebellum development during childhood and adolescence: a longitudinal morphometric MRI study. Neuroimage 49:63-70. CrossRef Medline

Wickham H (2007) Reshaping data with the \{reshape\} package. J Stat Softw 21:1-20.

Wickham H (2009) ggplot2: Elegant graphics for data analysis. New York: Springer.

Wierenga L, Langen M, Ambrosino S, van Dijk S, Oranje B, Durston S (2014) Typical development of basal ganglia, hippocampus, amygdala and cerebellum from age 7 to 24 . Neuroimage 96:67-72. CrossRef

Willemet R (2012) Understanding the evolution of Mammalian brain structures; the need for a (new) cerebrotype approach. Brain Sci 2:203-224. CrossRef Medline

Zijdenbos AP, Forghani R, Evans AC (2002) Automatic "pipeline" analysis of 3-D MRI data for clinical trials: application to multiple sclerosis. IEEE Trans Med Imaging 21:1280-1291. CrossRef Medline 